\begin{tabular}{|c|c|c|}
\hline$\triangle E$ & $\begin{array}{c}\text { European Association for the } \\
\text { Development of Renewable Energies, Environment } \\
\text { and Power Quality (EA4EPQ) }\end{array}$ & $\begin{array}{l}\text { International Conference on Renewable Energies and Power Quality } \\
\text { (ICREPQ' 12) } \\
\text { Santiago de Compostela (Spain), 28th to 30th March, } 2012\end{array}$ \\
\hline
\end{tabular}

\title{
Neural-Networks and Synchronous Reference Frame Applied in the Harmonic Compensation with a Three-Phase Parallel Active Power Filter
}

\author{
L. B. G. Campanhol ${ }^{1}$, A. Goedtel ${ }^{1}$, S. A. O. da Silva ${ }^{1}$ and C. F. Nascimento ${ }^{2}$ \\ ${ }^{1}$ Department of Electrical Engineering \\ UTFPR, Federal Technological University of Paraná \\ Av. Alberto Carazzai, 1640 - 86300-000 - Cornélio Procópio - Paraná (Brazil) \\ Phone/Fax number: +55 43 35204096; +55 4335204010 \\ e-mail: leo_campanhol@hotmail.com, agoedtel@utfpr.edu.br, augus@utfpr.edu.br \\ ${ }^{2}$ Center of Engineering (CECS) \\ UFABC, Federal University of ABC \\ Rua Santa Adelia, 166 - 09210-170 - Santo André - São Paulo (Brazil) \\ Phone/Fax number: +55 11 49968211; +55 1149960089 \\ e-mail: claudionor.nascimento@ufabc.edu.br
}

\begin{abstract}
This paper presents an alternative method based on artificial neural network, which is used to obtain the reference currents for harmonic current suppression and reactive power compensation in a shunt active power filter applied to three-phase four-wire system. The neural network consists of a multilayer perceptron, which is trained to estimate the peak amplitude of the load fundamental component currents. The performance of the proposed artificial neural network is evaluated by computer simulation, and it is compared with the method based on synchronous reference frame.
\end{abstract}

\section{Key words}

Active Power Filter, Artificial Neural Network, Harmonics, Power Quality.

\section{Introduction}

Equipments based on the power electronic connected to the power systems, such as switched power supply, cycloconverters, inverters for driving AC motors, controlled and non-controlled rectifiers for driving DC motors, among others, have been widely used in industrial, commercial and residential applications. However, the currents generated by these nonlinear loads can distort the utility voltages contributing to the degradation of the power quality (PQ) in the electrical power systems. The increasing of non-linear loads makes the use of active power filters an interesting way to eliminate harmonic currents as well as reactive power compensation.

An alternative method to minimize the problems related to the PQ is the use of parallel active power filters (PAPF), which is applied in single-phase systems as well as in three-phase three or four-wire systems [1]-[8]. The PAPF, based on voltage-source converter, injects compensation currents in order to cancel the harmonic and/or reactive components present in the load current.

Several techniques have been proposed in the literature to produce the compensation reference currents for active power filters.

A method based on the synchronous reference frame (SRF) has been largely used [6], [9]-[11]. Other methods are based on the use of an artificial neural network (ANN) [12]-[15], [18]. Such network can be used in the estimation of the harmonic content in electrical power systems.

This paper proposes an alternative method based on ANN to obtain the compensation reference currents to be used in a PAPF, which is applied to suppress the harmonic currents generated by three single-phase fullwave rectifiers feeding inductive-resistive loads $(R L)$, which are connected to a three-phase four-wire system.

The ANN uses the multilayer perceptron architecture in order to estimate the peak amplitude of the load fundamental component currents. Through this peak amplitude and using a synchronous single vector, obtained from a phase-locked loop (PLL) system [16], it is possible to obtain the compensation reference currents to be used by the PAPF.

Simulation results are presented with the purpose of showing the PAPF operation using an ANN for the generation of the compensation reference currents. The proposed method is compared to the SRF method to verify its effectiveness. 
The organization of this paper is described as follows: The PAPF topology using three full-bridge inverters is presented in Section 2. The SRF method is described in Section 3. The aspects related to the ANN are presented in Section 4. The simulation results of the proposed structure are demonstrated in Section 5. The conclusions of this paper are presented in Section 6.

\section{Topology of the three-phase PAPF}

Several topologies of voltage source inverters (VSIs) have been used to implement PAPFs, which are applied to three-phase four-wire systems [2]-[8]. In this paper, the PAPF structure is performed by means of three full-bridge topology, as shown in Fig. 1 [3], [6].

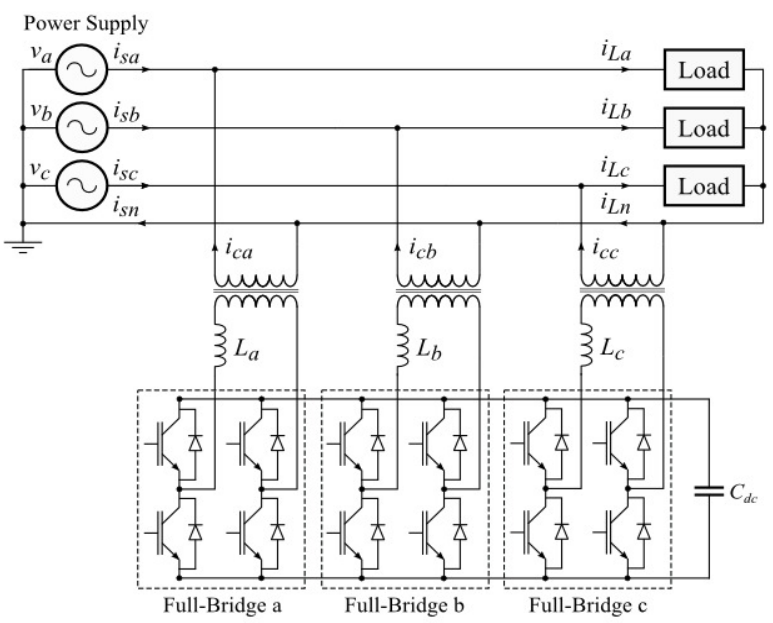

Fig. 1. PAPF structure using three full-bridge topologies.

This topology has three full-bridge single-phase inverters connected in each phase of the electrical system allowing independent control of all three phases.

Thus, depending on the compensation strategy chosen, the PAPF can perform reactive power compensation and current harmonic suppression. The load unbalance can be taking into account or not. Besides, the three VSI must be connected to the network through isolation transformers because they share the same dc-bus voltage.

\section{SRF in active power filter applications}

Compensators based on the SRF have been used to the harmonic compensation in active power filters, both in three-phase and single-phase systems [6], [9]-[11].

The SRF method proposes the changing of the fundamental terms of voltage and/or current from the $a b c$ stationary axes, to continuous quantities in the $d q$ synchronous axes, in which they spin at a synchronous speed in relation to the spatial vectors of voltage and/or current.

The harmonic parcels of voltage or current in the $d q$-axes, which have different frequencies on the synchronous frame, are represented as alternate terms superposed to the continuous terms. Thus, the fundamental parcels can be extracted by using low-pass filters (LPFs).

A PLL circuit, which is synchronized with the frequency of the electric system, synthesizes the unit vectors $\sin \theta$ and $\cos \theta$, ensuring the necessary orthogonality to the ideal functioning of the system.

\section{A. SRF applied to single-phase systems}

The SRF method will be applied to single-phase systems in order to obtain the compensation reference currents of the PAPF.

The compensation strategy will be performed to control each phase independently [3], [6].

This method consists in the individual measurement of the three-phase currents $\left(i_{L a}, i_{L b}, i_{L c}\right)$ and the application of a delay of $\pi / 2$ radians in each of them. The measured load currents are treated as the $\alpha$-axis currents of the fictitious two-phase stationary reference frame ( $\alpha \beta$-axes). Subsequently, the load currents $\left(i_{L_{a, b, c}}=i_{\alpha_{a, b, c}}\right)$ have a $\pi / 2$ radian phase delay, producing the fictitious quadrature currents in the $\beta$-axis $\left(i_{\beta_{a, b, c}}\right)$.

Therefore, three systems of fictitious two-phase stationary $\alpha \beta$-axes can be created as it is seen in (1).

$$
\left[\begin{array}{l}
i_{\alpha_{a, b, c}} \\
i_{\beta_{a, b, c}}
\end{array}\right]=\left[\begin{array}{c}
i_{L_{a, b, c}}(\omega t) \\
i_{L_{a, b, c}}(\omega t-\pi / 2)
\end{array}\right]
$$

For example, the current measured from the phase ' $a$ ' ( $i_{L_{a}}=i_{\alpha_{a}}$ ) has a $\pi / 2$ radians phase delay and $i_{\beta_{a}}$ is generated, as it can be seen in Fig. 3, where all the phases are considered. Thus, the two-phase fictitious axes are obtained directly from the measured currents, and the transformation from the $a b c$ stationary three-phase to the $\alpha \beta$ stationary two-phase system is not necessary.

Thereby, the method only needs of the transformations from the $\alpha \beta$ stationary two-phase to the $d q$ synchronous reference frame, according to the matrix of transformation presented in (2).

$$
\left[\begin{array}{l}
i d \\
i q
\end{array}\right]=\left[\begin{array}{cc}
\cos \theta & \sin \theta \\
-\sin \theta & \cos \theta
\end{array}\right] \cdot\left[\begin{array}{c}
i_{\alpha} \\
i_{\beta}
\end{array}\right]
$$

In order to extract the harmonic components of the load currents in the $d$-axis, a high-pass filter (HPF) is used, as implemented according to Fig. 2.

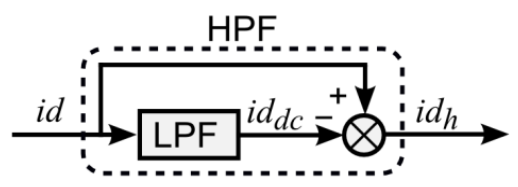

Fig. 2. HPF diagram 
The compensation reference currents of the PAPF $\left(i_{c a}^{*}, i_{c b}^{*}\right.$ and $i_{c c}^{*}$ ) are obtained by (3), in which they are obtained directly from the $d q$ synchronous axes.

$$
i_{c_{a, b, c}}^{*}=\left[\begin{array}{ll}
\cos \theta_{a, b, c} & -\sin \theta_{a, b, c}
\end{array}\right]\left[\begin{array}{l}
i d_{h_{a, b, c}} \\
i q_{a, b, c}
\end{array}\right]
$$

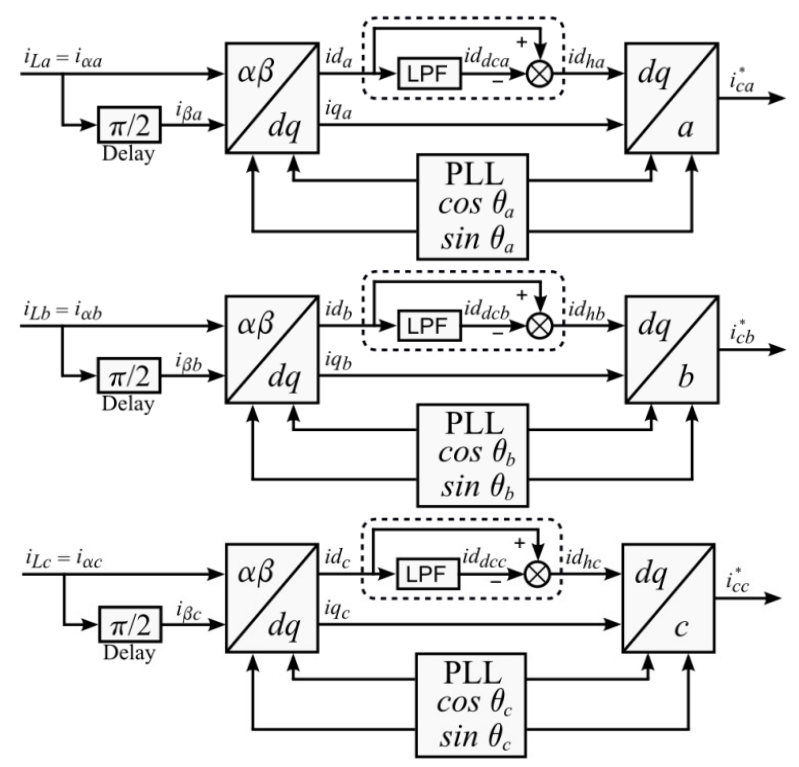

Fig. 3. Block diagrams of the SRF algorithm used individually per phase.

\section{Artificial Neural Network}

The ANNs represent a technology based on computational technics inspired on the neural biological structure, with the intention of simulating the human brain. These have the capacity of knowledge acquisition and maintenance and can be defined as a set of processing units, characterized by artificial neurons that are interconnected by a great number of interconnections [17]. Fig. 4 shows an artificial neuron diagram.

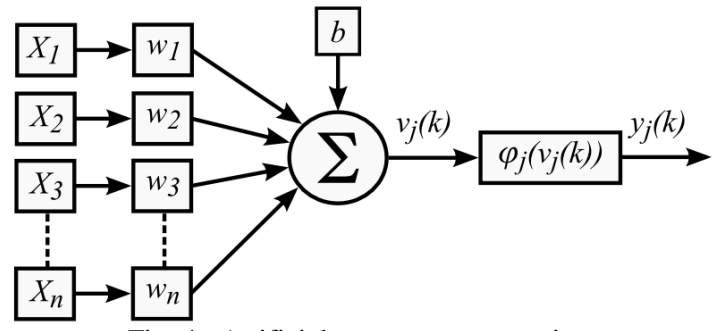

Fig. 4. Artificial neuron representation.

As it was described in [17], the mathematical model that represents the artificial neuron is given by (4) and (5).

$$
\begin{aligned}
& v_{j}(k)=\sum_{i=1}^{m} X_{i} \cdot w_{i}+b \\
& y_{j}(k)=\varphi_{j}\left(v_{j}(k)\right)
\end{aligned}
$$

where:

$v_{j}(k)$ is the answer of the $j$-th neuron;

$X_{i}$ is the $i$-th input signal;

$w_{i}$ is the weight associated to the $i$-th input;

$b$ is the threshold of each neuron;

$m$ is the number of neuron input signals;

$y_{j}(k)$ is the output signal of the $j$-th neuron;

$\varphi_{j}(k)$ is the activation function of the $j$-th neuron.

Each artificial neuron calculates its output signal, according to its respective input signal, through the adjustments of the synaptic weights associated to the $j$-th output neuron. This adjustment process is done through the calculation of the $e_{j}(k)$ error signal in relation to the $k$-th iteration of the $k$-th input vector, and this is calculated by (6).

$$
e_{j}(k)=d_{j}(k)-y_{j}(k)
$$

where $d_{j}(\mathrm{k})$ is the desired answer of the $j$-th output neuron.

Adding all the quadratic errors produced by the exit neurons of the network in relation to the $k$-th iteration, it is obtained:

$$
E(k)=\frac{1}{2} \sum_{j=1}^{p} e_{j}^{2}(k)
$$

where $p$ is the number of output neurons. In order to obtain a great configuration of weights, $E(k)$ is minimized through the adjustment of the $w_{j i}$ synaptic weights. The weights associated to network output layer are recalculated by (8).

$$
w_{j i}(k+1)=w_{j i}(k)-\eta \frac{\partial E(k)}{\partial w_{j i}(k)}
$$

The $w_{j i}$ synaptic weight is connected to the $j$-th neuron of the layer considered to the $i$-th neuron of the previous layer, where $\eta$ is the constant that determines the learning rate of the retropropagation algorithm. The adjustment of the weights that belong to the hidden layers is done through an analogous way, and it is better described in [17].

\section{A. ANN applied in the PAPF}

Nowadays, several applications related to the PQ themes using the ANN have been proposed in the literature [12][15].

In this paper, a neural network is used in each phase of the PAPF. Each neural network is formed by a multilayer perceptron (MLP), with supervised training. The MLP estimates the peak value of the load fundamental component currents $\left(I_{L p 1}\right)$, to obtain the compensation reference currents of the proposed PAPF. 
Each MLP network is composed by two neural networks, the hidden layer is composed by fifteen neurons and the exit layer is composed by one neuron (Fig. 5). The activation functions used are hyperbolic tangent in the hidden layer and linear in the output layer.

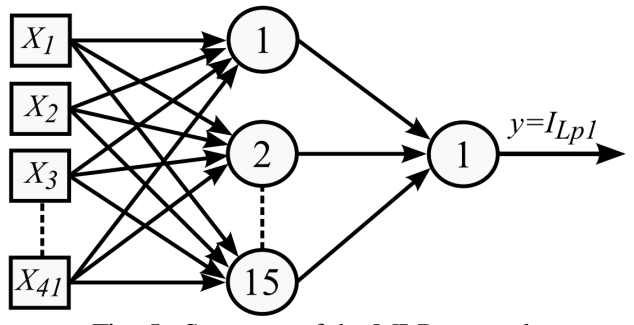

Fig. 5. Structure of the MLP network.

The nonlinear load used to obtain the samples of the MLP network training consists of a single-phase full-wave rectifier with $R L$ load. Table I shows different power rates of the load.

Table I. Load parameters to ANN training.

\begin{tabular}{|c|c|c|}
\hline \multicolumn{3}{|c|}{ Single-phase full-wave rectifier with $R L$ load } \\
\hline Resistance & Inductance & Power \\
\hline $10 \Omega$ & $250 \mathrm{mH}$ & $1450 \mathrm{VA}$ \\
\hline $12 \Omega$ & $250 \mathrm{mH}$ & $1200 \mathrm{VA}$ \\
\hline $14 \Omega$ & $250 \mathrm{mH}$ & $1050 \mathrm{VA}$ \\
\hline $16 \Omega$ & $250 \mathrm{mH}$ & $900 \mathrm{VA}$ \\
\hline $18 \Omega$ & $250 \mathrm{mH}$ & $800 \mathrm{VA}$ \\
\hline $20 \Omega$ & $250 \mathrm{mH}$ & $720 \mathrm{VA}$ \\
\hline $22 \Omega$ & $250 \mathrm{mH}$ & $650 \mathrm{VA}$ \\
\hline $24 \Omega$ & $250 \mathrm{mH}$ & $600 \mathrm{VA}$ \\
\hline $26 \Omega$ & $250 \mathrm{mH}$ & $550 \mathrm{VA}$ \\
\hline $28 \Omega$ & $250 \mathrm{mH}$ & $520 \mathrm{VA}$ \\
\hline
\end{tabular}

For each power level described in Table I, the current signal of the load $\left(i_{L}\right)$ was acquired and properly conditioned, to obtain the set of necessary samples to be used in the training process of the MLP network. Fig. 6 shows the block diagram of the process to obtain the samples that were used in the MLP network training.

The desired output of the MLP network is the peak value of the load fundamental component current $\left(I_{L p l}\right)$, which is obtained from the LPF output $\left(i d_{d c}\right)$ of the synchronous axis in the SRF method (Fig. 3).

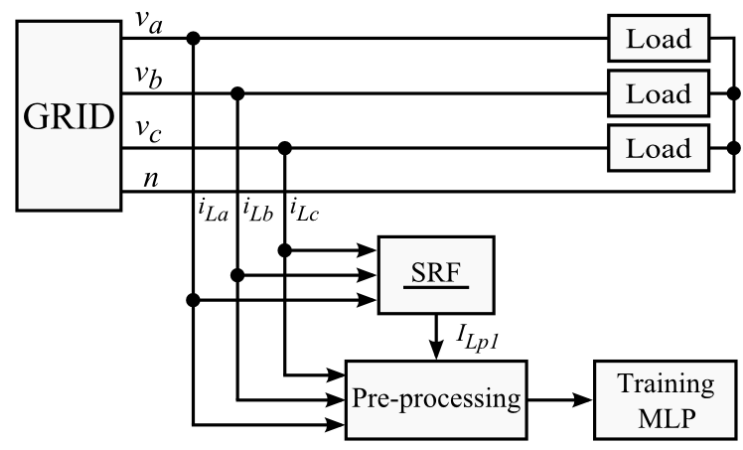

Fig. 6. Diagram of the training process.

\section{Validation of the MLP network}

In order to validate the studies in the MLP network, it was tested in the PAPF through computer simulations. The simulations were carried out considering a threephase four-wire system, with rms phase voltage of $127 \mathrm{~V}$ and a frequency of $60 \mathrm{~Hz}$. For the validation, different power rates of the load were used in the training process, according to Table II.

Table II. Load parameters to ANN validation.

\begin{tabular}{|c|c|c|c|}
\hline \multicolumn{4}{|c|}{ Single-phase full-wave rectifier with $R L$ load } \\
\hline Phase & Resistance & Inductance & Power \\
\hline A & $11.6 \Omega$ & $250 \mathrm{mH}$ & $1250 \mathrm{VA}$ \\
\hline B & $14.5 \Omega$ & $250 \mathrm{mH}$ & $1000 \mathrm{VA}$ \\
\hline $\mathrm{C}$ & $19.3 \Omega$ & $250 \mathrm{mH}$ & $750 \mathrm{VA}$ \\
\hline
\end{tabular}

In the validation process, the MLP network is trained online in order to estimate $I_{L p l}$. Using the estimated peak value and the synchronous unit vector $(\cos \theta)$, obtained from the PLL system, the fundamental part of the load current $\left(i_{f}\right)$ is achieved. Subtracting the quantity $i_{L}$ from $i_{l}$, the compensation reference current of the PAPF $\left(i_{c}^{*}\right)$ is obtained.

Fig. 7 shows the block diagram used in the acquiring process of the phase ' $a$ ' compensation reference current $\left(i_{c a}^{*}\right)$.

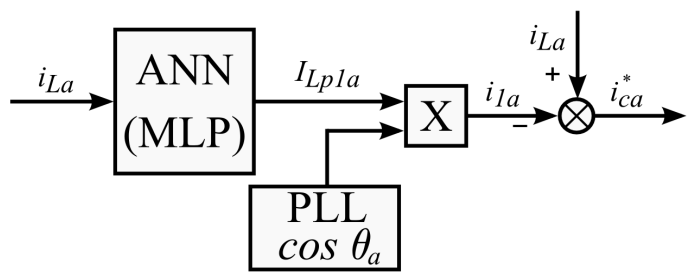

Fig. 7. Block diagram of the compensation reference current

$$
\left(i_{c a}^{*}\right) \text { acquisition process. }
$$

Figures 8 to 11 show the results concerning to the phase ' $a$ '. Fig. 8 shows the comparison between $I_{L p l a}$ obtained from both SRF method and MLP network, and the comparison related to the compensation reference currents $i_{c a}^{*}$ is shown in Fig. 9.

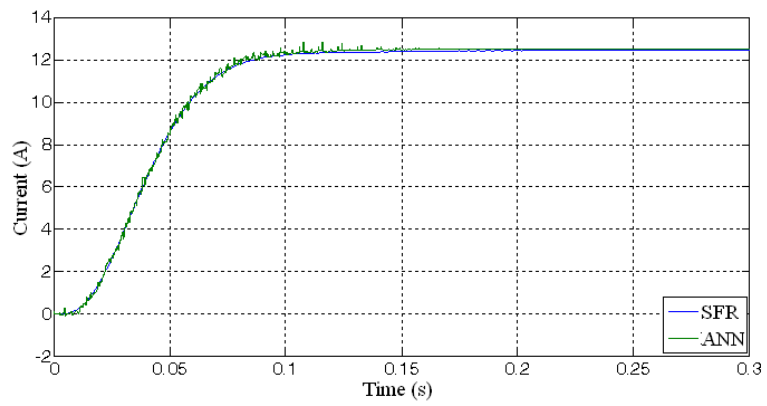

Fig. 8. Peak value of the phase 'a' load fundamental component current $\left(I_{\text {Lpla }}\right)$. 


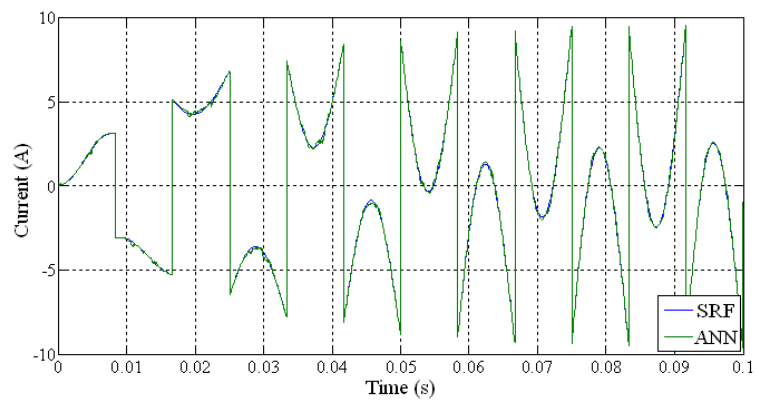

Fig. 9. Phase ' $a$ ' compensation reference current $\left(i_{c a}^{*}\right)$.

Figure 10 shows the load current $\left(i_{L a}\right)$, source current $\left(i_{s a}\right)$ and compensation current $\left(i_{c a}\right)$ synthesized by the PAPF.

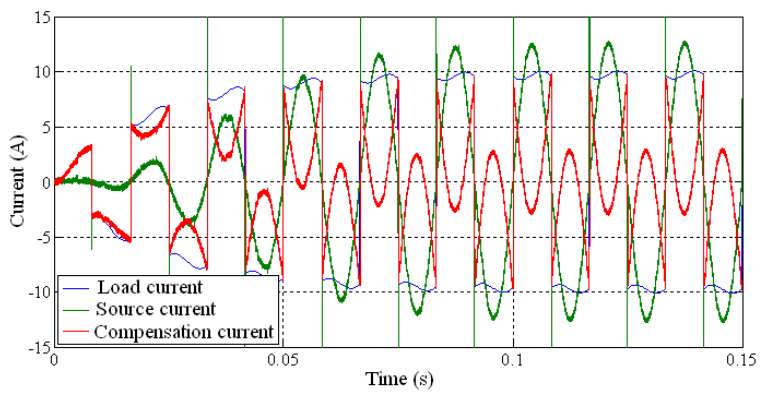

Fig. 10. Phase ' $a$ ' currents: $i_{L a}, i_{s a}$, and $i_{c a}$.

Figure 11 shows the load current $\left(i_{L a}\right)$ and the source current $\left(i_{s a}\right)$ when load transient occurs at $0.15 \mathrm{~s}$. It is possible to verify the capacity of the MLP operation considering this condition.

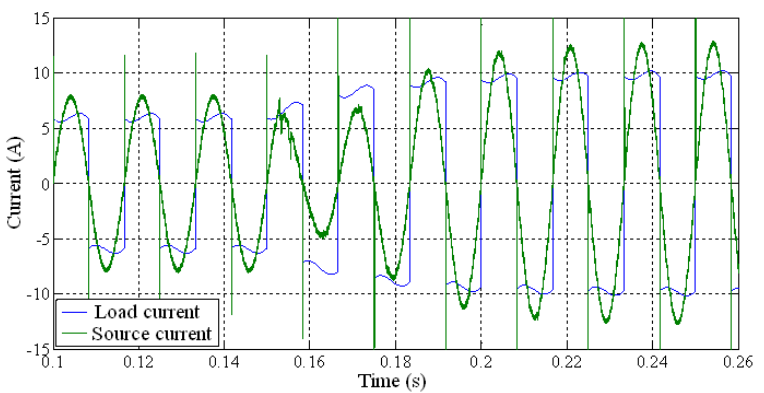

Fig. 11. $i_{L a}$ and $i_{s a}$ currents for load transient.

Figures 12 and 13 show the load current, source current and the compensation current of the phases ' $b$ ' and ' $c$ ', respectively.

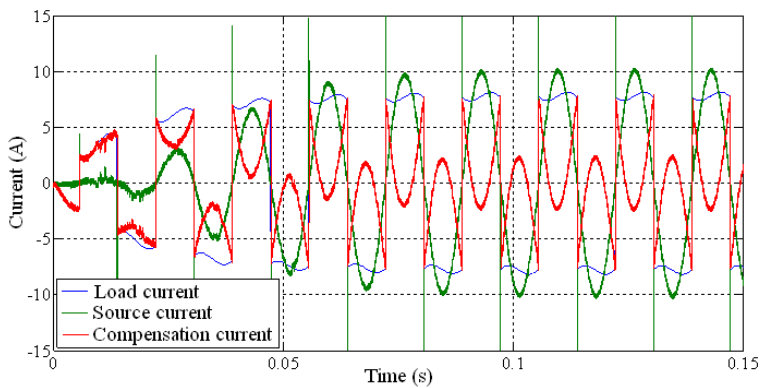

Fig. 12. Phase ' $b$ ' currents: $i_{L b}, i_{s b}$, and $i_{c b}$.

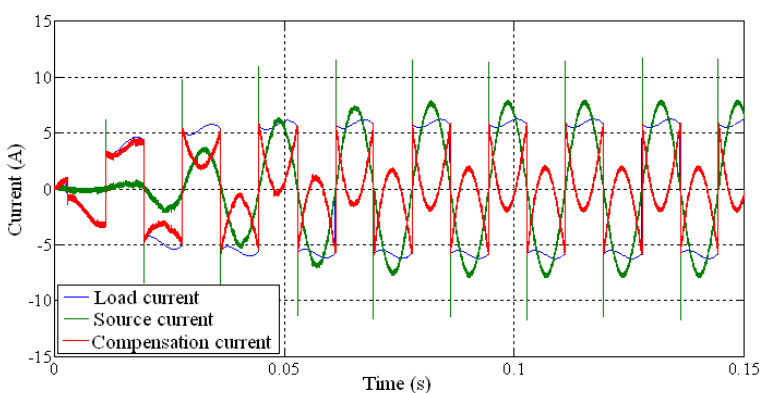

Fig. 13. Phase 'c' currents: $i_{L c}, i_{s c}$, and $i_{c c}$.

Table III shows the mean relative error (MRE) and the standard deviation (SD), calculated among $I_{L p 1}$ obtained from the SRF method and the MLP network.

Table III. MRE and SD.

\begin{tabular}{|c|c|c|}
\hline Phases & MRE (\%) & SD (\%) \\
\hline A & 1.06 & 1.54 \\
\hline B & 1.68 & 4.85 \\
\hline C & 2.26 & 3.36 \\
\hline
\end{tabular}

Table IV shows the total harmonic distortion (THD) of the three-phase source currents measured after the compensation of the load harmonic currents.

Table IV. Total Harmonic Distortion of the Source Currents (THD\%)

\begin{tabular}{|c|c|c|c|}
\hline Source Currents & $i_{s a}$ & $i_{s b}$ & $i_{s c}$ \\
\hline Without compensation & 47.35 & 47.31 & 47.16 \\
\hline SRF method & 1.56 & 1.41 & 1.55 \\
\hline MLP network & 1.59 & 1.45 & 1.33 \\
\hline
\end{tabular}

\section{Conclusion}

This paper presented an alternative method, based on neural networks, in order to obtain the compensation reference currents of a three-phase PAPF used to suppress harmonic currents generated by nonlinear loads.

The MLP network estimated the peak values of the fundamental components of the nonlinear three-phase load currents. Using the fundamental peak values and the synchronous unit vectors obtained from PLL systems, the PAPF compensation reference currents were obtained.

The validation of the MLP network presented the effectiveness of the proposed ANN in the generation of the reference currents. Besides, the obtained results were very similar to those obtained from the SRF method.

According to the application of the compensation reference currents, it was possible to verify the performance of the PAPF in suppression of load harmonic currents. 


\section{Acknowledgement}

The authors gratefully acknowledge the financial support received from $\mathrm{CNPq}$, processes $\mathrm{n}^{0} 474290 / 2008-5, \mathrm{n}^{\circ}$ 471825/2009-3, and 480352/2010-0, and from Araucária Foundation, process $\mathrm{n}^{\circ} 06 / 56093-3$.

\section{References}

[1] H. Akagi, "Active harmonic filters", in Proc. of the IEEE, vol 93, no.12, pp 2128-2141, 2005.

[2] R. Camargo and R. Pinheiro, "Three-phase four-wire shunt active filter to reduce voltage and current distortions on the distribution systems", 32nd Annual Conference of the IEEE Industrial Electronics Society, 2006.

[3] V. Khadkikar and A. Chandra, "An independent control approach for three-phase four-wire shunt active filter based on three h-bridge topology under unbalanced load conditions", 39th IEEE Power Electronics Specialists Conference, 2008.

[4] M. I. M. Monteiro, E. R. Cadaval and F. B. González, "Comparison of control strategies for shunt active power filters in three-phase four-wire system", IEEE Trans. on Power Electronics, vol. 22, no. 1, pp. 229-236, 2007.

[5] R. Pregitzer, J. C. Costa, J. S. Martins and J. L. Afonso, "Simulation and implementation results of a 3-phase 4-wire shunt active power filter", International Conference on Harmonics and Quality Power, 2006.

[6] S. A. O. Silva, A. Feracin, S. G. S. Cervantes, A.Goedtel and C. F. Nascimento, "Synchronous reference frame based controllers applied to shunt active power filters in threephase four-wire systems", IEEE International Conference on Industrial Technology, ICIT 2010.

[7] B. Singh, K. A. Haddad and A. Chandra, "A reeview of active filters for power quality improvement" IEEE Trans. on Industrial Electronics, vol. 46, no. 5, pp. 960-971, 1999.

[8] O. Vodyakho, T. Kim and S. Kwak, "Three-level based active power filter for the three-phase, four-wire system", in Proc. 39th IEEE Power Electronics Specialists Conference, PESC 2008.

[9] S. Bhattacharya, D. M. Divan and B. B. Banerjee, "Synchronous frame harmonic isolator using active series filter", 4th European Conference on Power Electronics and Applications, EPE 1991.

[10] S. Bhattacharya, T. M. Frank, D. M. Divan and B. Banerjee, "Parallel active filter system implementation and design issues for utility interface of adjustable speed drive systems," in Proc. IEEE IAS Annual Meeting, 1996, pp. 1032-1039.

[11] S. A. O. Silva and R. A. Modesto, "A comparative analysis of SRF-based controllers applied to active power line conditioners", 34th Annual Conference of the IEEE Industrial Electronics Society. IECON 2008.

[12] D. O. Abdeslam, P. Wira, J. Mercklé, D. Flieller and Y. A. Chapuis, "A unified artificial neural network architecture for active power filters", IEEE Transaction on Industrial Electronics, vol 54, no.01, pp 61-76, 2007.

[13] C. F. Nascimento, A. A. O. Junior, A. Goedtel, P. J. A. Serni and S. A. O. Silva, "Harmonic content identification based on neural method for single phase power systems", 13th European Power Electronics Conference and Applications. EPE 2009.

[14] C. F. Nascimento, A. A. O. Junior, A. Goedtel, I. N. Silva and P. J. A. Serni, "Neural network-based approach for identification of the harmonic content of a nonlinear load in a single-phase system", IEEE Latin America Transactions, vol. 8, no. 1, pp. $65-73,2010$
[15] S. R. D. Naoussi, H. Berviller, J. P. Blondé, C. H. Kom, M. Kom and F. Braun, "FPGA implementation of harmonic detection methods using neural networks", 13th European Conference on Power Electronics and Applications, EPE 2009.

[16] S. A. O. Silva, L. B. G. Campanhol, A. Goedtel, C. F. Nascimento and D. Paião, "A comparative analysis of pPLL algorithms for single-phase utility connected systems", 13th European Power Electronics Conference and Applications, EPE 2009.

[17] S. Haykin, Neural Networks and Learning Machines, Prentice Hall, 2008.

[18] Y. Han, M. M. Khan, G. Yao, L. Zhou and C. Chen, "A novel harmonic-free power factor corrector based on Ttype APF with adaptive linear neural network (ADALINE) control", Simulation Modelling Pratice and Theory 16, pp 1215-1238, 2008. 